\title{
Variability of sputum inflammatory mediators in COPD and $\alpha_{1}$-antitrypsin deficiency
}

\author{
Helen Stone, Gillian McNab, Alice M. Wood, Robert A. Stockley and Elizabeth Sapey
}

ABSTRACT: There is inherent daily variability of sputum inflammatory mediators in stable-state patients with usual chronic obstructive pulmonary disease (COPD). The variability of pulmonary inflammation in patients with $\alpha_{1}$-antitrypsin deficiency (A1ATD) is unknown. Our study aimed to quantify this variability, in comparison to patients with usual COPD, in order to facilitate power calculations for proof of concept trials of putative specific anti-inflammatory agents in both groups.

Sputum interleukin (IL)-8, myeloperoxidase (MPO), leukotriene $\mathrm{B}_{4}\left(\mathrm{LTB}_{4}\right)$ and differential cell counts were measured in 12 usual COPD patients and 12 A1ATD patients on nine occasions over a 1-month period. All samples were obtained in the stable clinical state.

There was significant daily variability in all mediators in all patients. A1ATD patients had higher sputum concentrations of IL-8 and LTB 4 compared with usual COPD, but lower levels of MPO and absolute neutrophil counts. Patients with usual COPD had more intra-patient variability, A1ATD patients demonstrated greater inter-patient variability.

There are increased concentrations of pulmonary inflammatory mediators but fewer sputum neutrophils in A1ATD compared with usual COPD. The daily variability of inflammatory mediators and cell counts was significantly reduced in both groups by averaging sequential samples. This can be utilised to perform power calculations for future proof of concept studies; averaging three sequential samples appears optimum.

KEYWORDS: $\alpha_{1}$-antitrypsin deficiency, chronic obstructive pulmonary disease, inflammatory mediators, sputum

hronic obstructive pulmonary disease (COPD) is a common, progressive and debilitating inflammatory disease [1] with limited treatment [2]. The neutrophilic inflammation present in stable disease does not consistently respond to inhaled corticosteroids [2], no therapies have been shown to prevent disease progression and improve mortality [3, 4]. The disease is heterogeneous and the response to universal treatments in generic cohorts of COPD patients is limited $[5,6]$. It may be that patients need to be stratified into defined phenotypes to gain maximum benefit from new therapies. Utilising traditional primary end-points, such as a reduction in forced expiratory volume in $1 \mathrm{~s}$ (FEV1) decline, is prohibitively expensive due to the patient numbers required. However, small, short-term studies in phase II are essential, using appropriate and well-characterised patients in order to identify potentially effective therapies.

Pulmonary inflammation is thought to be central to the development and progression of COPD, with in vivo and in vitro evidence supporting the role of the neutrophil in pathophysiology [7]. Neutrophilic inflammation correlates with disease severity $[8,9]$ and is elevated in disease phenotypes associated with poorer outcomes, such as chronic bronchitis [10] and patients with frequent exacerbations [11]. Inflammatory mediators have been used in limited studies, e.g. antibodies against interleukin (IL)-8 [12] and small molecule antagonists of leukotriene $B_{4}$ $\left(\mathrm{LTB}_{4}\right)$ [13]. However, interpretation of these studies has been hampered by small, poorly defined patient groups and inappropriate clinical end-points.

\section{AFFILIATIONS}

School of Clinical and Experimental Medicine, University of Birmingham, Birmingham, UK.

\section{CORRESPONDENCE}

E. Sapey

School of Clinical and Experimental Medicine

University of Birmingham Birmingham

B15 2TT

UK

E-mail: liz.sapey@aol.co.uk

Received:

Sept 192011

Accepted after revision:

Dec 212011

First published online:

June 142012 
Previous studies described variability of inflammatory mediators in spontaneous sputum from stable patients with usual COPD and chronic bronchitis and explored the effects of multiple sampling on reducing variability [14]. In the stable state, there is significant day-to-day variability in the concentrations of inflammatory mediators, both within (intra-patient) and between patients (inter-patient). This intra-patient variability can be reduced using the average of sequential daily samples [14]. Spontaneous sputum is particularly suited to serial collection, as it reflects airways inflammation, has no inflammatory sequalae and is acceptable to most patients (in contrast to induced sputum and bronchoalveolar lavage) [15].

With this information, phase II clinical trials can be adequately powered to detect a predetermined change in mediator concentrations. This is fundamental for phase II trials that need appropriate anti-inflammatory end-points to establish the potential of long-term efficacy. Lung physiology may not always be the most appropriate end-point as it is slow to change and may take years to demonstrate a difference in decline.

Patients with $\alpha_{1}$-antitrypsin deficiency (A1ATD) account for $2 \%$ of patients with COPD, and have a similar spectrum of lung disease compared to patients with usual COPD. However, clinically significant disease tends to be diagnosed at a younger age and following less cigarette smoke exposure [16]. $\alpha_{1^{-}}$ antitrypsin $\left(\alpha_{1}-\mathrm{AT}\right)$ inhibits neutrophil elastase on a one-to-one molar basis and reduced concentrations of circulating $\alpha_{1}$-AT are less able to inhibit neutrophil elastase released during cell migration, frustrated phagocytosis and cell necrosis, thereby leading to excessive tissue damage [17].

A1ATD is also a heterogeneous condition, and patients differ in their clinical phenotypes and rates of decline [18]. Up to $40 \%$ of patients with A1ATD have a chronic bronchitis phenotype [19], compared with $30 \%$ of patients with usual COPD [20]. A1ATD is associated with increased evidence of inflammation compared to usual COPD [21, 22], but the daily variability of sputum inflammatory mediators has not been assessed within A1ATD patients.

The aims of this study were three-fold. First, to study inflammatory mediators and cells in a cohort of patients with closely matched A1ATD and usual COPD. Secondly, to describe and compare the variability in inflammatory mediators in the sputum of patients with usual COPD and A1ATD. Thirdly, to generate data to facilitate power calculations for phase II interventional studies.

\section{MATERIALS AND METHODS}

12 patients with the PiZZ phenotype of A1ATD were recruited from the Antitrypsin Deficiency Assessment and Programme for Treatment (ADAPT) register. Patients were selected because they had chronic bronchitis as defined by the Medical Research Council criteria [23]. Post-bronchodilator spirometry was performed to confirm the presence of airflow obstruction. Gas transfer was assessed by single breath carbon monoxide transfer according to Association for Respiratory Technology and Physiology guidelines [24], and quantitative computed tomography (CT) was used to measure the extent of emphysema. $\alpha_{1}$ AT levels were measured by immunoassay and phenotype was identified by isoelectric focusing, confirmed by genotyping (Heredilab, Salt Lake City, UT, USA).
12 patients with usual COPD (matched for disease severity classified by Global Initiative for Chronic Obstructive Lung Disease guidance, gas transfer, sex, body mass index, exacerbation frequency and treatment) were recruited from a tertiary centre clinic. The COPD patients also underwent spirometry, an assessment of gas transfer and had concomitant lung pathology excluded both clinically and by a high-resolution CT scan. Patients with evidence of bronchiectasis were excluded. All usual COPD patients had their $\alpha_{1}$-AT levels measured to exclude A1ATD.

\section{Study design}

Patients were reviewed on nine occasions over 1 month: daily for 5 days, then on days 7, 14, 21 and 28. During the study patients were asked to complete a daily diary card [25]. All patients were clinically stable throughout the study (confirmed by daily diary, clinical interview and examination) and had not had an exacerbation or changes in treatment during the study or for the preceding 8 weeks. At each visit, samples of blood and spontaneous sputum were collected and diary cards, symptoms, smoking intensity and treatments were reviewed. Spirometry was performed on days $1,7,14$ and 28 to assess stability [23].

\section{Sputum collection and processing}

Sputum was collected on each occasion for a 4-h period from waking. Mouth washing procedures were employed (with a discarded double rinse with water prior to sputum expectoration and collection) to reduce the possibility of contamination from saliva. Patients who were current smokers were asked to refrain from doing so during the collection period. Sputum samples were divided into three aliquots. The first was ultracentrifuged at $50,000 \times g$ for $90 \mathrm{~min}$ at $4^{\circ} \mathrm{C}$ to obtain sputum soluble phase, as described previously [26]. The soluble phase was used to measure mediator concentrations including IL-8, myeloperoxidase (MPO) and $\mathrm{LTB}_{4}$. The second was treated with dithiothreitol and cytospins prepared for total and differential cell counts of squamous cells, neutrophils and macrophages [27]. The final aliquot was used for quantitative bacterial culture to assess colonisation.

\section{Measurement of mediators}

Mediator concentrations of IL-8 and $\mathrm{LTB}_{4}$ were measured in duplicate using Enzyme Amplification Sensitivity Immunoassay (R\&D Systems, Abingdon, UK) and the results expressed in molar concentrations. Each of these assays had been previously validated [26]. For all mediators, the intra- and inter-assay variability was $<10 \%$, and all mediator concentrations were above both the lower limit of detection and quantification for the assay. MPO was measured using an in-house assay, validated previously and quantified as $\mathrm{mg} \cdot \mathrm{mL}^{-1}[22]$.

\section{Statistical analysis}

Data analysis was performed using SPSS (version 17.0; SPSS, Chicago, IL, USA). Normally distributed data are expressed using mean $\pm \mathrm{SD}$. Non-normally distributed data (e.g. mediator concentrations and cell counts) were log transformed to achieve normality in order to calculate coefficients of variance (CV).

To study the effects of serial sampling on the intra-patient variability of mediators, the means of multiple data points were assessed [14]. First, 3-day means were calculated using 
data from days 1, 2 and 3;2, 3 and 4; 3, 4 and 5, etc., and subsequently the effects of 5 days; thus, $1,2,3,4$ and $5 ; 2,3,4,5$ and 6 until 5, 6, 7, 8 and 9 .

Using variability data, power calculations for both a two-group parallel comparison and a paired (crossover) comparison were performed using the following formulae.

For a parallel design:

$$
n=1+2 C(S / D)^{2}
$$

For a crossover design:

$$
\mathrm{n}=1+\mathrm{C}(\mathrm{S} / \mathrm{D})^{2}
$$

where $\mathrm{D}$ was the smallest difference to be detected (for illustrative purposes, an arbitrary effect of $50 \%$ reduction in mediator concentration was chosen) and $S$ represented the standard deviation of the observations. $\mathrm{C}$ is a constant of 7.85 to provide an $80 \%$ power of detecting a reduction in mean mediator concentration at the 5\% level of significance [28].

All participants provided written, informed consent and all studies were approved by the South Birmingham Research Ethics Committee (LREC number 3359) in accordance with good clinical practice.

\section{RESULTS}

24 patients were enrolled into the study and baseline characteristics are shown in table 1 . The main significant difference between the groups was age (A1ATD patients were typically younger). There were more current smokers among patients with usual COPD. Among the A1ATD patients, most patients were ex-smokers, two were active smokers, and one had never smoked. The A1ATD patients attend a national centre for this condition, and smoking cessation is reinforced at every visit. There was no significant difference in pack-year history between the two patient groups, although this may reflect small patient numbers. Quantitative sputum culture confirmed that no patient was colonised with potential respiratory pathogens throughout the study. At each visit, diary cards, symptoms and medications were reviewed, and clinical examination was performed. No patients experienced an exacerbation during the study, and there were no significant changes in symptoms, clinical indices, smoking intensity, treatment or recorded spirometry (data not shown). All patients provided a sputum and blood sample at each visit.

\section{Mediator concentrations}

Patients with A1ATD had higher concentrations of IL-8 and $\mathrm{LTB}_{4}$ than those with usual COPD but notably significantly lower concentrations of both absolute sputum neutrophil counts and MPO. There were no differences in absolute sputum macrophage counts between groups (table 2).

\section{Variability in mediator concentrations}

There was considerable variability in the concentrations of mediators and cells within individual patients. Figure 1 demonstrates the variability seen in mediator and cell concentrations for one patient with A1ATD and one patient with usual COPD. Table E1 (online supplementary data) summarises the median data for each mediator and the cell count for each patient.

Intra-patient variability (a measure of the changes in the concentrations of sputum mediators and cell counts within individual subjects) was calculated from the mean and SD of each patient's log-transformed data from all nine visits, expressed as the CV. Intra-patient variability was not related to changes in individual symptoms (as recorded in the patients' diary), clinical features or lung function (all of which remained stable). MPO intra-patient variability was significantly greater in usual COPD than A1ATD, suggesting that these measurements or sample dilution fluctuated more dayto-day within individual patients than those with A1ATD. The

TABLE 1 Baseline characteristic for patients included in the study

\begin{tabular}{lcc} 
Characteristics & A1ATD group & Usual COPD \\
\hline Subjects $\mathbf{n}$ & 12 & 12 \\
Age yrs & $50(33-66)$ & $61(57-67)^{\star \star}$ \\
Male & $9(75)$ & $5(42)$ \\
FEV1 L & $0.95 \pm 0.47$ & $0.91 \pm 0.3$ \\
FVC L & $3.0 \pm 0.87$ & $3.05 \pm 0.77$ \\
FEV 1 /FVC \% & $30.4 \pm 9.2$ & $37.1 \pm 8.9$ \\
TL,CO \% pred & $49.2 \pm 11.6$ & $58.9 \pm 15.2$ \\
BMI kg m $^{-2}$ & $23.9 \pm 3.86$ & $23.2 \pm 4.1$ \\
Current smokers & $2(16.7)$ & $7(58)$ \\
Pack-yr history & $29.0 \pm 18.2$ & $38.5 \pm 17.7$ \\
Patients on long-acting bronchodilators & $11(92)$ & $12(100)$ \\
Patients on ICS & $6(50)$ & $7(58)$ \\
Patients on long-acting inhaled anti-muscurinics & $9(75)$ & $10(83)$ \\
Exacerbations in preceding year & $4(2-5)$ & $3(1-6)$
\end{tabular}

Data are presented as median (interquartile range), $n(\%)$ or mean $\pm \mathrm{SD}$, unless otherwise stated. A1ATD: $\alpha_{1}$-antitrypsin deficiency; COPD: chronic obstructive pulmonary disease; FEV1: forced expiratory volume in $1 \mathrm{~s}$; FVC: forced vital capacity; $T \mathrm{~L}, \mathrm{CO}$ : transfer factor of the lung for carbon monoxide; \% pred: \% predicted; BMI: body mass index; ICS: inhaled corticosteroids. ${ }^{* *}: \mathrm{p}<0.01$. 


\begin{tabular}{|c|c|c|c|}
\hline \multirow[t]{2}{*}{ TABLE 2} & \multicolumn{3}{|c|}{$\begin{array}{l}\text { Inflammatory mediators and cells for } \alpha_{1} \text {-antitrypsin deficiency (A1ATD) patients and disease severity-matched controls } \\
\text { with usual chronic obstructive pulmonary disease (COPD) }\end{array}$} \\
\hline & & A1ATD & Usual COPD \\
\hline \multicolumn{2}{|l|}{ IL-8 nM } & $11.29(1.80-20.46)$ & $3.72(1.41-13.72)^{\star \star}$ \\
\hline \multicolumn{2}{|l|}{ MPO $\mathrm{mg} \cdot \mathrm{mL}^{-1}$} & $0.78(0.46-2.10)$ & $1.77(1.12-3.53)^{*}$ \\
\hline \multicolumn{2}{|c|}{$\mathrm{LTB}_{4} \mathrm{nM}$} & $12.16(3.85-37.84)$ & $6.10(1.35-17.81)^{\star *}$ \\
\hline
\end{tabular}

Data are presented as overall median (interquartile range). The overall median is calculated using the average mediator concentration or cell count from each of the nine visits for each subject in each patient group. IL: interleukin; MPO: myeloperoxidase; $\mathrm{LTB}_{4}$ : leukotriene $\mathrm{B}_{4}$. ${ }^{*}: \mathrm{p}<0.05$; ${ }^{*}$ : $p<0.01$.

converse relationship was seen for sputum neutrophil counts, which were higher in patients with A1ATD (table 3). There were no significant differences in the variance of other mediators or macrophage counts.

Intraclass correlation coefficients were calculated for each of the mediators in both patient groups. The intraclass correlation reflected the intra-patient $\mathrm{CV}$; so where the intra-patient $\mathrm{CV}$ was high, the intraclass correlation coefficients were generally low and vice versa. However, the results show that in A1ATD, whereas the intra-patient $\mathrm{CV}$ for $\mathrm{MPO}$ and $\mathrm{LTB}_{4}$ are similar (36.0 and 32.0, respectively), the intraclass correlation coefficients are different at 0.931 and 0.634 , respectively. This may be due to the fact that intra-patient CVs assess within patient variability relative to the means for patients, whereas intraclass correlations assess within patient variability relative to the within patient variability. The data are shown in table 4.

There was significant inter-patient variability in mediator and cell counts. Inter-patient variability was calculated from the logtransformed mean biomarker value for all patients, expressed as the CV. This variability was primarily driven by a small number of patients. Of note, three patients with A1ATD and two with usual COPD had mean concentrations of all mediators and cell counts that were at least double those of the group median. $\mathrm{LTB}_{4}$ is shown as an example in figure 2. Importantly, there were no specific clinical characteristics (age, sex, lung physiology, lung imaging, smoking history, medications or bacterial colonisation), which differentiated these patients from their peers.

There was significantly greater variance in MPO between patients with A1ATD than those with usual COPD. There were no other differences in the inter-patient variability of other mediators and cell counts (table 5).

\section{Reducing variability}

The effect of using a rolling mean

When comparing a single mediator within patients, a significant reduction in variability (as determined by CV) was obtained using a 3-day rolling mean in all mediators and cell counts. No further reduction in variability was seen using a 5-day rolling mean. Figure 3 compares variability in mediator concentrations
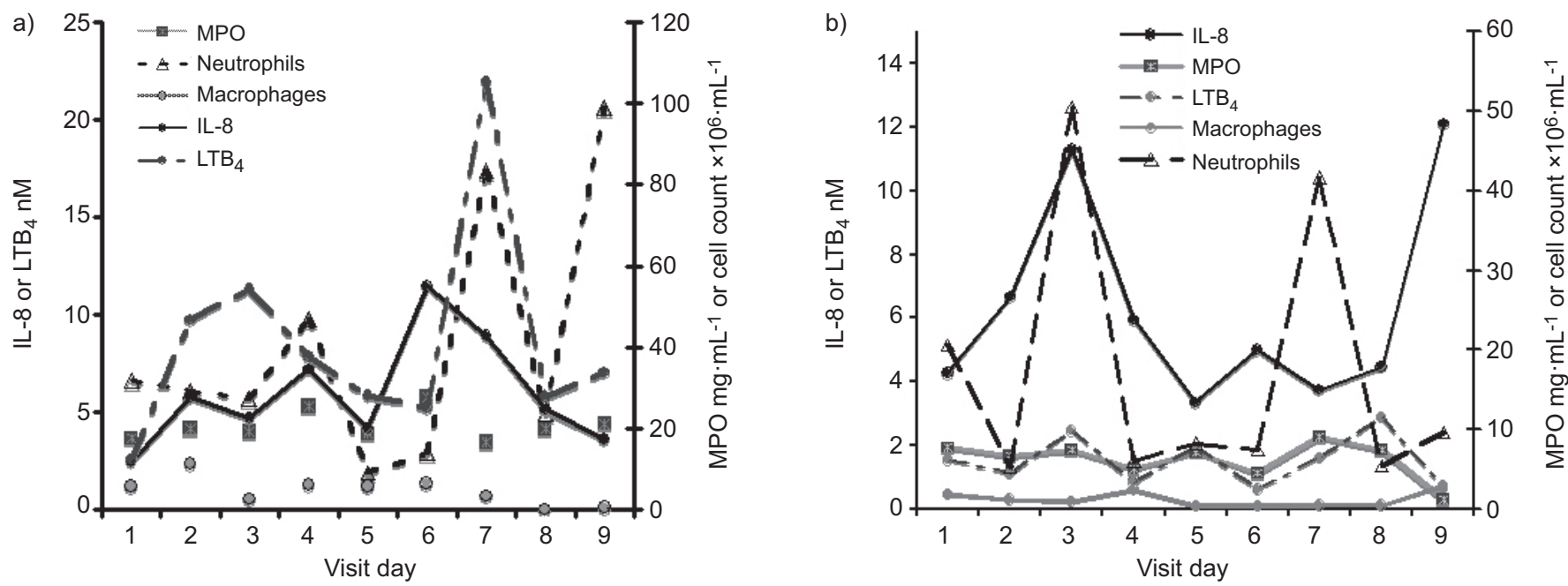

FIGURE 1. Changes in the concentrations of sputum soluble phase mediators for patients with $\alpha_{1}$-antitrypsin deficiency (A1ATD) and a patient with usual chronic obstructive pulmonary disease (COPD) during the study period. a) Changes in raw data over 1 month for an A1ATD patient for the sputum soluble mediators interleukin (IL)-8 $(\mathrm{nM})$, myeloperoxidase (MPO; $\left.\mathrm{mg} \cdot \mathrm{mL}^{-1}\right)$ and leukotriene $(\mathrm{LTB})_{4}(\mathrm{nM})$, and sputum absolute neutrophil and macrophage counts (cells $\left.\times 10^{6} \cdot \mathrm{mL}^{-1}\right)$ for each visit. b) Changes in raw data over 1 month for a matched usual COPD patient for the sputum soluble mediators IL-8, MPO and $\mathrm{LTB}_{4}$, and sputum absolute neutrophil and macrophage counts for each visit. 
TABLE 3 Intra-patient variability of sputum inflammatory mediators and cell counts in matched stable patients with usual chronic obstructive pulmonary disease (COPD) and $\alpha_{1}$-antitrypsin deficiency (A1ATD)

\begin{tabular}{lccccc} 
& IL-8 & MPO & LTB $_{\mathbf{4}}$ & Sputum neutrophils & Sputum macrophages \\
\hline A1ATD & $28.9(14.5-74.0)$ & $36.0(18.3-44.3)$ & $32.0(20.8-53.7)$ & $69.4(67.2-117.2)$ & $111.2(85.6-154.5)$ \\
COPD & $45.1(22.0-88.1)$ & $72.2^{* *}(42.8-85.7)$ & $45.5(14.8-122.9)$ & $23.0^{*}(18.6-33.3)$ & $71.4(37.5-97.9)$ \\
\hline
\end{tabular}

Data are presented as coefficient of variant (CV) median \% (interquartile range). The median intra-patient (within patient) CV is derived from individual patients mediatorspecific CV, calculated using logged data from nine visits. IL: interleukin; MPO: myeloperoxidase; $\mathrm{LTB}_{4}$ : leukotriene $\mathrm{B}_{4} .{ }^{*}$ : $p<0.05$; ${ }^{\star *}: \mathrm{p}<0.01$

and the effect of rolling means for one representative patient with A1ATD and one with usual COPD. Table E2 (online supplementary data) describes the changes in intra-patient $\mathrm{CV}$ observed when using data from a single day, or a 3- or 5-day rolling mean for each patient.

\section{Determining the sample size required to power interventional studies}

Once intra-patient and inter-patient variability was determined in each group, calculations could be performed to assess the numbers needed to power clinical studies of a putative therapy adequately, where a reduction in mediator concentration or cell count would be the primary end-point.

Using a cross-over design, the number of patients needed to observe a $50 \%$ reduction in sputum neutrophil counts using a single data point per patient in A1ATD would be 93. However, if the data from 3 days is used, the number needed to detect the same reduction would be 61 , and 41 with a 5-day average.

In usual COPD, using a cross-over design, the number of patients needed to see a $50 \%$ reduction in sputum neutrophil counts using a single data point per patient would be 26 . If a 3 -day average is used, the number needed to detect the same reduction would be 5 , and 4 with a 5 -day average.

$\begin{array}{ll}\text { TABLE } 4 & \begin{array}{l}\text { Intraclass correlation coefficients of sputum } \\ \text { inflammatory mediators and cell counts in } \\ \text { matched stable patients with usual chronic } \\ \text { obstructive pulmonary disease (COPD) and } \\ \alpha_{1} \text {-antitrypsin deficiency (A1ATD) }\end{array} \\ & \\ \text { A1ATD } & 0.818(0.664-0.935) \\ \text { IL-8 } & 0.931(0.858-0.977) \\ \text { MPO } & 0.634(0.419-0.852) \\ \text { LTB } & 0.170(0.101-0.258) \\ \text { Neutrophil count } & 0.139(0.088-0.200) \\ \text { Macrophage count } & \\ \text { COPD } & 0.746(0.558-0.905) \\ \text { IL-8 } & 0.577(0.357-0.82) \\ \text { MPO } & 0.798(0.633-0.927) \\ \text { LTB }_{4} & 0.365(0.166-0.674) \\ \text { Neutrophil count } & 0.654(0.432-0.871) \\ \text { Macrophage count } & \end{array}$

Data are presented as intraclass correlation (95\% confidence intervals). IL: interleukin; MPO: myeloperoxidase; $\mathrm{LTB}_{4}$ : leukotriene $\mathrm{B}_{4}$.
Table 6 summarises the average number of patients required to detect similar changes in mediators and macrophage counts when a single sample is collected or when the average of the first three or five consecutive samples is used for power calculations in both patient groups. Table E3 (online supplementary data) presents the same data where a parallel study design is used.

\section{DISCUSSION}

These unique studies of inflammatory biomarkers were performed in extensively phenotyped patients with A1ATD and matched patients with usual COPD, all with chronic bronchitis. Patients with A1ATD had higher concentrations of IL-8 and $\mathrm{LTB}_{4}$ in their sputum, compared with patients with usual COPD, and supports previous reports [21, 29].

Interestingly, concentrations of $\mathrm{MPO}$ and absolute neutrophil counts were lower in A1ATD compared with usual COPD. There are no published data that directly compare concentrations of MPO and neutrophil counts from which to draw comparison; however, the values gained for the other inflammatory mediators in this study are similar to previously published data for both patient groups [14, 15, 30-32] suggesting our results are robust. It may be that the differences in neutrophilic inflammation reflect greater neutrophil retention in the tissues of A1ATD due to the local accumulation of polymers [33], or a greater chemotactic response of neutrophils

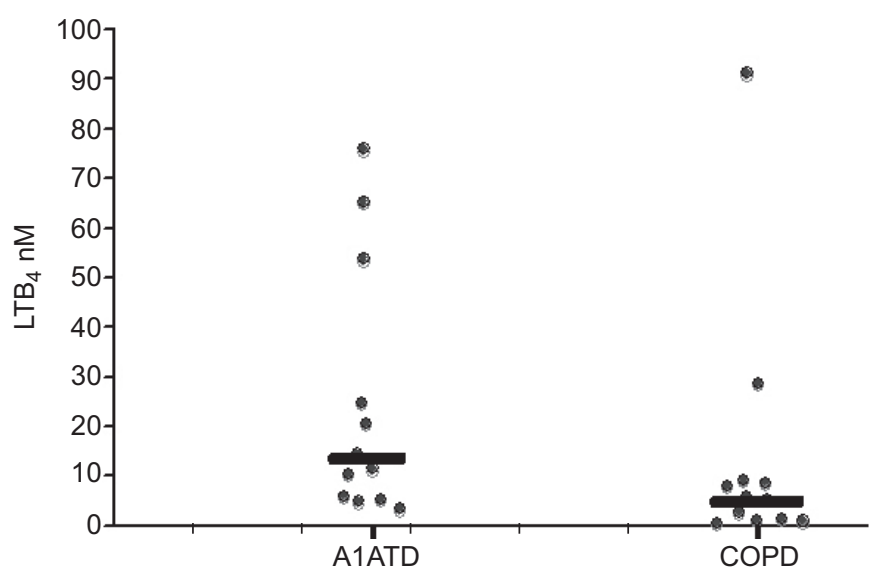

FIGURE 2. Median concentrations of leukotriene (LTB $)_{4}$ in patients with $\alpha_{1}$ antitrypsin deficiency (A1ATD) and usual chronic obstructive pulmonary disease (COPD). Each data point represents one patient. Overall, patients with A1ATD had a higher median concentration of $\mathrm{LTB}_{4}$ compared to patients with usual COPD $(p<0.01)$, despite notable outliers in each patient group. 


\begin{tabular}{llllll} 
TABLE 5 & $\begin{array}{l}\text { Inter-patient variability of sputum inflammatory } \\
\text { mediators and cell counts in matched stable } \\
\text { patients with usual chronic obstructive } \\
\text { pulmonary disease } \\
\text { deficiency (A1ATD) }\end{array}$ \\
& IL-8 & MPO & LTB $_{\mathbf{4}}$ & $\begin{array}{c}\text { Sputum } \\
\text { neutrophils }\end{array}$ & $\begin{array}{c}\text { Sputum } \\
\text { macrophages }\end{array}$ \\
\hline A1ATD & 78.9 & 230.1 & 51.1 & 29.1 & 35.7 \\
COPD & 99.3 & $78.3^{* *}$ & 71.1 & 20.6 & 58.0 \\
\hline
\end{tabular}

Data are presented as coefficient of variance $(\mathrm{CV})$ as \%. The inter-patient (between patients) $\mathrm{CV}$ is derived from individual patient's mediator-specific mean and SD (from logged data), calculated using data from nine visits. IL: interleukin; MPO: myeloperoxidase; $\mathrm{LTB}_{4}$ : leukotriene $\mathrm{B}_{4}{ }^{*}$ : $p<0.01$.

from COPD patients [34]. Differences between groups were influenced by a subset of patients who displayed consistently higher pulmonary inflammation during the study than their matched peers. Nonetheless, differences in mediator concentrations and cell counts remained significant when these outliers were excluded. Great efforts were taken to ensure patients were clinically stable; exacerbations do not account for the differences seen. Although subjects with A1ATD were significantly younger and there was a trend towards fewer active smokers, higher sputum cell counts and concentration of mediators was not associated with age or smoking status. Indeed, patients with A1ATD had higher concentrations of inflammatory mediators in their sputum despite more being ex-smokers, suggesting that the higher inflammatory load was not a reflection of smoking status. Importantly, studies have suggested that active smoking per se does not significantly affect inflammatory profile [35]. The higher burden of IL-8 and $\mathrm{LTB}_{4}$ in pulmonary secretions from patients with A1ATD would be consistent with the anti-inflammatory role of $\alpha_{1}$-AT and the pro-inflammatory role of its cognate protein (neutrophil elastase).

Sputum dilution, especially with oropharyngeal secretions, could have affected mediator concentration. Although we took the precaution of the patients rinsing their mouths prior to
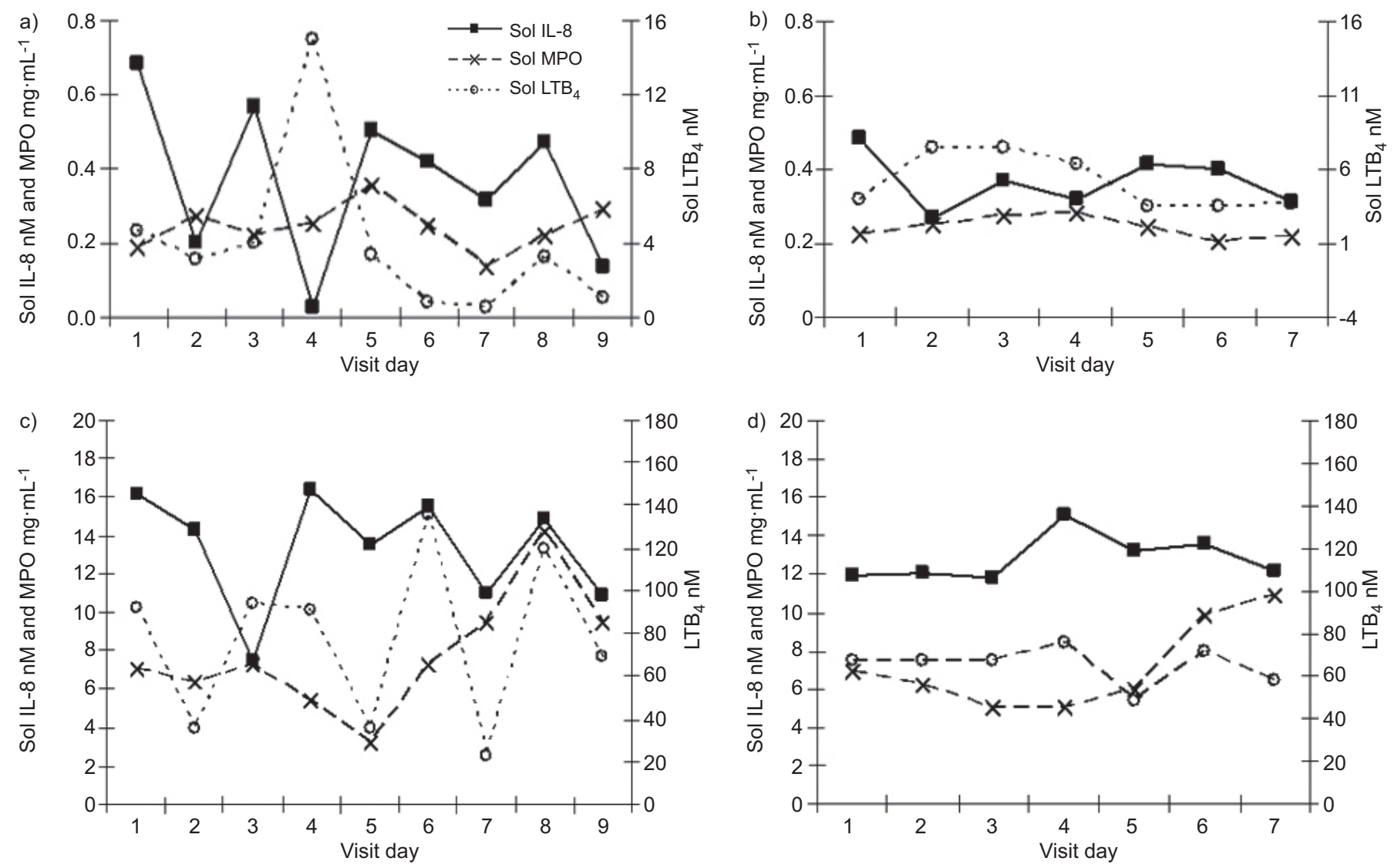

FIGURE 3. Changes in intra-patient variability in three mediators using data from nine sequential visits or a 3-day rolling mean in a patient with $\alpha_{1}$-antitrypsin deficiency (A1ATD) and a patient with usual chronic obstructive pulmonary disease (COPD). a) Changes in the concentrations of soluble (sol) phase mediators for a patient with A1ATD during the study period. Each data point represents the measured concentration of one mediator for a single patient for a single visit. b) Changes in the concentrations of soluble phase mediators for the same A1ATD patient using a 3-day rolling mean. Each data point represents the mean measured concentration of each mediator for three consecutive days. c) Changes in the concentrations of soluble phase mediators for a patient with COPD during the study period. Each data point represents the measured concentration of one mediator for a single patient for a single visit. d) Changes in the concentrations of soluble phase mediators for the same COPD patient using a 3-day rolling mean. Each data point represents the mean measured concentration of each mediator for three consecutive days. IL: interleukin; MPO: myeloperoxidase; LTB 4 : leukotriene $\mathrm{B}_{4}$. 


\begin{tabular}{|c|c|c|c|c|c|c|c|c|c|c|}
\hline TAB & $\begin{array}{l}\text { A cc } \\
\text { mea } \\
\text { dise }\end{array}$ & $\begin{array}{l}\text { rison o } \\
5 \text { days } \\
\text { COPD }\end{array}$ & $\begin{array}{l}\text { umber } \\
\text { ed for }\end{array}$ & $\begin{array}{l}\text { ded in } \\
\text { ations }\end{array}$ & $\begin{array}{l}\text { s-over } \\
\text { ntitryp }\end{array}$ & $\begin{array}{l}\text { / desig } \\
\text { ficienc }\end{array}$ & $\begin{array}{l}\text { en data } \\
\text { ATD) an }\end{array}$ & $\begin{array}{l}1 \text { day, } \\
\text { lal chrc }\end{array}$ & $\begin{array}{l}\text { hean of } \\
\text { bstructi }\end{array}$ & $\begin{array}{l}\text { S or the } \\
\text { Imonary }\end{array}$ \\
\hline \multirow[t]{2}{*}{ Days } & \multicolumn{2}{|c|}{ IL-8 } & \multicolumn{2}{|c|}{ MPO } & \multicolumn{2}{|c|}{$\mathrm{LTB}_{4}$} & \multicolumn{2}{|c|}{ Neutrophil } & \multicolumn{2}{|c|}{ Macrophage } \\
\hline & A1ATD & COPD & A1ATD & COPD & A1ATD & COPD & A1ATD & COPD & A1ATD & COPD \\
\hline 5 & 4 & 6 & 26 & 9 & 5 & 4 & 31 & 4 & 38 & 10 \\
\hline
\end{tabular}

Data are presented as the numbers required to provide an $80 \%$ chance of detecting a $50 \%$ decrease in mediators or cells at the $5 \%$ level of significance. Power calculations were performed for each mediator or cell using data from the first study visit for 1 day data. Power calculations were performed using data collected on the first 3 days (visit 1 to 3 ) or the first 5 days for 3 and 5 day data, respectively. IL: interleukin; MPO: myeloperoxidase; LTB 4 : leukotriene $B_{4}$.

expectoration, the rinse itself or any remaining oropharyngeal secretions could still dilute the samples. This could explain some of the observed intra-patient variability and similar effects could influence the between patient variability. However, this is unlikely to explain differences seen in mediator and cell concentrations between groups; because, if this were the case, we would expect both mediators and cells in each patient to be either high (concentrated secretions) or low (dilute secretions). Instead, A1ATD patients had higher levels of chemoattractants, but lower levels of MPO, a combination that would not occur by dilution alone. Although our sample size is small, median results were collated from nine sequential samples from every patient; all measurements were replicated, making measurement error unlikely.

There are no data that can explain why some patients appear to have a higher burden of pulmonary inflammation and why the usual COPD patients had more MPO and neutrophils in pulmonary secretions. Even in these well-characterised and closely matched cohorts of patients, there is significant interpatient variation in inflammatory profiles (immunophenotypes) [14, 36, 37] and clinical outcomes [8, 38, 39], suggesting FEV1 alone is insufficient to predict clinical course or response to anti-inflammatory treatment. Cigarette smoking remains the most important risk factor for the development of COPD $[40,41]$, suggesting that a combination of genetic and environmental factors interact to cause COPD. There has been much research aimed at identifying candidate genes that may confer genetic susceptibility, even in A1ATD.

Differences in inflammation could, therefore, be driven by different genotypes [37] and it is likely that other uncommon pro-inflammatory polymorphisms may co-exist [7] that influence inflammatory phenotype and, potentially, responses to specific anti-inflammatory treatments. It may be that patients with a higher burden of inflammation have an as yet unidentified polymorphism, which in combination with A1ATD drives a more aggressive form of the disease, although this currently remains largely speculative.

There is evidence of aberrant neutrophil migration in usual COPD [42], which is not present in A1ATD [43, 44], and differences in the adherence and speed of migrating neutrophils in COPD could, theoretically, lead to an increased neutrophil presence and degranulation in the airways, despite lower concentrations of chemoattractants, potentially explaining the lower neutrophil numbers in A1ATD despite higher chemoattractant concentrations.

As seen previously in usual COPD [14, 45, 46], there was significant day-to-day variability in measured inflammatory mediators and cells. These are the first studies of serial measurements in A1ATD and hence the first direct comparison between A1ATD and usual COPD. Interestingly, there was more intra-patient daily variability in MPO concentrations within usual COPD patients, greater sputum neutrophil variability in A1ATD patients and more inter-patient variability for the same measurements in A1ATD. We speculate that $\mathrm{MPO}$, which is a marker of neutrophil degranulation, may vary more within patients with usual COPD due to differences in neutrophil behaviour in this disease $[42,43]$.

It is unclear why patients with A1ATD display inter-patient heterogeneity. Differences may be due, in part, to: 1) inter-subject variation in circulating levels of $\alpha_{1}-\mathrm{AT}$, which vary even between subjects with deficiency, but would remain constant within an individual; 2) the presence of polymers, believed to be chemotactic for neutrophils [47]; or 3) the presence of interacting genetic influences. Despite the variability noted both within and between patients, power calculations performed in the current study confirm that concentrations of sputum inflammatory mediators and cells require significantly less patients to power studies adequately than the clinical indices reported to date [48-50], making them attractive end-points in early proof of concept trials.

A 3-day rolling mean had the optimal effect on intra-patient variability and supports its use as a technique for studying inflammation in interventional studies in both A1ATD and usual COPD. Two 3-day collections of spontaneous sputum (pre- and post-intervention) in each patient would provide a sound basis for interpreting inflammatory changes following treatment. There were differences in power calculations between patients with A1ATD and usual COPD, particularly when data from a single day was used, and especially when using cell counts. Multiple data points reduced numbers predicted by power calculations for both groups.

There is also a decrease in the variability following a 5-day collection in some mediators, which slightly reduces the numbers required to adequately power studies. Overall, this further reduction is not significant from 3 days of sampling, and would 
require both greater patient compliance and cost. Hence, 3 days appears to be optimum in terms of gaining the greatest reduction in variability and patient numbers, whilst remaining practical in terms of consecutive sample collection.

Our groups were closely matched, with the exception of current smoking status, as there were fewer A1ATD patients who were current smokers, although the pack-year history was not statistically different between the groups, which may be a possible limitation of our study. Irrespective of this, our study highlights the fundamental importance of performing power calculations in the subject group to be studied, using the endpoints of interest, as data collected from similar patients may not necessarily reflect simple extrapolation.

Our study focused on patients with A1ATD and usual COPD with a chronic bronchitis phenotype. Chronic bronchitis is of prognostic importance as mucus hypersecretion is recognised to be associated with an excess FEV1 decline, increased risk of hospitalisation [51] and increased mortality from respiratory infections [52]. Inflammatory airway burden appears higher in patients who chronically expectorate sputum [10] and there is evidence of differential treatment responses in patients with COPD and chronic bronchitis, such as the increased efficacy of the phosphodiesterase- 4 inhibitor, roflumilast [5]. In light of this, there is increasing importance in studying this phenotype in COPD, as it is probable that this disease characteristic will require a different treatment strategy to patients without chronic sputum production.

Spontaneous sputum was chosen as its collection is noninvasive, can be repeated daily, does not evoke an inflammatory response in the airways, is minimally operator dependent and does not introduce an artificial dilution factor, making it an ideal medium for serial studies, compared with induced sputum or bronchoalveolar lavage $[15,53]$. It does, however, prohibit the inclusion of healthy controls. It has been well established that the mediators and cells measured in this study are increased in COPD compared with healthy controls [54, 55] and the aims of this study were to document the variability of measured mediators and their inter-relationships in spontaneous sputum samples from patients with A1ATD and COPD. Data for sequential induced sputum or lavage are not available, but it is likely that the inter-patient variability of a single sample is equally wide and sample dilution by saline is potentially more of a problem. Repeated sampling is far less practical and pro-inflammatory in its' own right. The use of sputum, therefore, has the advantage of repeat sampling to overcome these issues and is thus ideal for relevant proof of concept studies.

In conclusion, the current study documents the daily variability in sputum inflammatory mediator concentrations in the stable state of both usual COPD and those with A1ATD. The data demonstrate a higher cytokine inflammatory load in the sputum of patients with A1ATD, despite more variability in patients with usual COPD. The variability was not associated with changes in symptomatology and the intra-patient variability was reduced by averaging sequential samples, rather than using a single data point. This approach can be used in practice when conducting clinical trials, as using sequential sampling significantly reduces the number of patients needed to power proof of concept studies. In patients with usual COPD and A1ATD, averaging three daily samples seemed optimum. The choice of mediator to use for a study will vary depending on the underlying disease, and a small pilot study with power calculations to determine the variability should be undertaken. We suggest the strategy employed here should be a critical first step.

\section{STATEMENT OF INTEREST}

A statement of interest for R.A. Stockley can be found at www.erj. ersjournals.com/site/misc/statements.xhtml

\section{REFERENCES}

1 Global Initiative for Chronic Obstructive Lung Disease. Global Strategy for Diagnosis, Management and Prevention of COPD. Updated 2011. www.goldcopd.org/Guidelines/guidelines-resources.html.

2 Barnes PJ. Emerging pharmacotherapies for COPD. Chest 2008; 134: 1278-1286.

3 Calverley PA, Sanchez-Toril F, McIvor A, et al. Effect of 1 year treatment with roflumilast in severe chronic obstructive pulmonary disease. Am J Respir Crit Care Med 2007; 176: 154-161.

4 Calverley PA, Anderson JA, Celli BC, et al. Salmeterol and fluticasone propionate and survival in chronic obstructive pulmonar disease. N Engl J Med 2007; 356: 775-789.

5 Rennard SI, Calverley PM, Goethring UM, et al. Reduction of exacerbations by the PDE4 inhibitor roflumilast - the importance of defining different subsets of patients with COPD. Respir Res 2011; [Epub ahead of print DOI:10.1186/465-9921-12-18].

6 Burge PS, Calverley PM, Jones PW, et al. Randomised, doubleblind, placebo controlled study of fluticasone propionate in patients with moderate to severe chronic obstructive pulmonary disease. The ISOLDE trial. BMJ 2000; 320: 1297-1303.

7 Sapey E, Stockley RA. The neutrophil and its special role in chronic obstructive pulmonary disease. In: Barnes PJ, Drazen JM, Rennard SI, et al., eds. Asthma and COPD: Basic Mechanisms and Clinical Management. 2nd Edn. London, Elsevier Publishing, 2008; pp. 173-192.

8 Donaldson GC, Seemungal TA, Patal IS, et al. Airway and systemic inflammation and decline in lung function in patients with COPD. Chest 2005; 128: 1995-2004.

9 Parr DG, White AJ, Bayley DL, et al. Inflammation in sputum relates to progression of disease in COPD: a prospective study. Respir Res 2006; 7: 136.

10 Gompertz S, Hill AT, Bayley D, et al. Effect of expectoration on inflammation in induced sputum in alpha-1-antitrypsin deficiency. Respir Med 2006; 100: 1094-1099.

11 Gompertz S, Bayley D, Hill SL, et al. Relationship between airway inflammation and the frequency of exacerbations in patients with smoking related COPD. Thorax 2001; 56: 36-41.

12 Mahler DA, Huang S, Tabrizi M, et al. Efficacy and safety of a monoclonal antibody recognizing interleukin-8 in COPD: a pilot study. Chest 2004; 126: 926-934.

13 Gompertz S, Stockley RA. A randomised controlled trial of a leukotriene synthesis inhibitor in patients with COPD. Chest 2002; 112: 289-294.

14 Sapey E, Bayley D, Ahmad A, et al. Inter-relationships between inflammatory markers in stable COPD patients with bronchitis: the intra and inter patient variability. Thorax 2008; 63: 493-499.

15 Barnes PJ, Chowdhury B, Kharitonov SA, et al. Pulmonary biomarkers in chronic obstructive pulmonary disease. Am J Respir Crit Care Med 2006; 174: 6-14.

16 Dowson LJ, Guest PJ, Stockley RA. Longitudinal changes in physiological, radiological, and health status measurements in $\alpha_{1-}$ antitrypsin deficiency and factors associated with decline. Am J Respir Crit Care Med 2001; 164: 1805-1809. 
17 Stockley RA. Neutrophils and the pathogenesis of COPD. Chest 2002; 121: Suppl., 151S-155S.

18 Dawkins PA, Dawkins CL, Wood AM, et al. Rate of progression of lung function impairment in $\alpha_{1}$-antitrypsin deficiency. Eur Respir J 2009; 33: 1338-1344.

19 Brantly ML, Paul LD, Miler BH, et al. Clinical features and history of the destructive lung disease associated with alpha-1-antitrypsin deficiency of adults with pulmonary symptoms. Am Rev Respir Dis 1988; 138: 327-336.

20 Cerveri I, Brusasco V. Revisited role for mucus hypersecretion in the pathogenesis of COPD. Eur Respir Rev 2010; 19: 109-112.

21 Woolhouse IS, Bayley D, Stockley RA. Sputum chemotactic activity in chronic obstructive pulmonary disease: effect of alpha 1 anti-trypsin deficiency and the role of leukotriene B4 and interleukin 8. Thorax 2002; 57: 709-714.

22 Hill AT, Bayley D, Stockley RA. The interrelationship of sputum inflammatory markers in patients with chronic bronchitis. Am J Respir Crit Care Med 1999; 160: 893-898.

23 Association for Respiratory Technology and Physiology. The ARTP Practical Handbook of Respiratory Function Testing. Part One. 2nd Edn. 2009. www.artp.org.uk/en/education/artp-books/ atrp-part-1-handbook.cfm.

24 Woolhouse IS, Hill SL, Stockley RA. Symptom resolution assessed using a patient directed diary card during treatment of acute exacerbations of chronic bronchitis. Thorax 2001; 56: 947-953.

25 MacIntyre N, Crapo RO, Viegi G, et al. Standardisation of the single-breath determination of carbon monoxide uptake in the lung. Eur Respir J 2005; 26: 720-735.

26 Stockley RA, Bayley D. Validation of assays for inflammatoy mediators in sputum. Eur Respir J 2000; 15: 778-781.

27 Woolhouse IS, Bayley DL, Stockley RA. Effect of sputum processing with dithiothreitol on the detection of inflammatory mediators in chronic bronchitis and bronchiectasis. Thorax 2002; 57: 667-771.

28 Snedecor GW, Cochran WG, eds. Statistical Methods. 8th Edn. Oxford, Wiley-Blackwell, 1989.

29 Voekel M, Voeke NF, MacNee W, eds. Chronic Obstructive Lung Disease. Shelton, PMPH-USA Publishing, 2008; pp. 56-60.

30 Gamble E, Qiu Y, Wang D, et al. Variability of bronchial inflammation in chronic obstructive pulmonary disease: implications for study design. Eur Respir J 2006; 27: 293-299.

31 Hill AT, Bayley DL, Campbell EJ, et al. Airways inflammation in chronic bronchitis: the effects of smoking and $\alpha_{1}$-anti-trypsin deficiency. Eur Respir J 2000; 15: 886-890.

32 O'Shaughnessy TC, Ansari TW, Barnes NC, et al. Inflammation in bronchial biopsies of subjects with chronic bronchitis: inverse relationship of CD8+ T lymphocytes with FEV1. Am J Respir Crit Care Med 1997; 155: 852-857.

33 Kelly E, Greene CM, Carroll TP, et al. Alpha-1 antitrypsin deficiency. Respir Med 2010; 104: 763-772.

34 Selby C, Drost E, Lannan S, et al. Neutrophil retention in the lungs of pateints with chronic obstructive pulmonary disease. Am Rev Respir Dis 1991; 143: 1359-1364.

35 Gamble E, Grootendorst DC, Hattotuwa K, et al. Airway mucosal inflammation in COPD is similar in smokers and ex-smokers: a pooled analysis. Eur Respir J 2007; 30: 467-471.

36 Siva R, Green RH, Brightling CE, et al. Eosinophillic airway inflammation and exacerbations of COPD: a randomised controlled trial. Eur Respir J 2007; 29: 906-913.

37 Sapey E, Wood AM, Ahmad A, et al. TNF- $\alpha$ rs361525 polymorphism is associated with increased local production and downstream inflammation in COPD. Am J Respir Crit Care Med 2010; 180 192-199.

38 Donaldson GC, Seemungal TA, Bhowmik A, et al. Relationship between exacerbation frequency and lung function decline in chronic obstructive pulmonary disease. Thorax 2002; 57: 847-852.

39 Stansecu D, Sanna A, Veriter C, et al. Airways obstruction, chronic expectoration and rapid decline in FEV1 in smokers are associated with increased levels of sputum neutropils. Thorax 1996; 51: 267-271.

40 Doll R, Peto R, Wheatley K, et al. Mortality in relation to smoking: 40 years' observations on male British doctors. BMJ 1994; 309: 901-911.

41 Tashkin DP, Clark VA, Coulson AH, et al. The UCLA population studies of chronic obstructive respiratory disease. VIII. Effects of smoking cessation on lung function; a prospective study of a freeliving population. Am Rev Respir Dis 1984; 130: 707-715.

42 Burnett D, Chamba A, Hill SL, et al. Neutrophils from subjects with chronic obstructive lung disease show enhanced chemotaxis and extracellular proteolysis. Lancet 1987; 2: 1043-1046.

43 Sapey E, Stockley JA, Greenwood H, et al. Behavioural and structural differences in migrating peripheral neutrophils from patients with chronic obstructive pulmonary disease. Am J Resp Crit Care Med 2011; 183: 1176-1186.

44 Woolhouse IS, Bayley DL, Lalor P, et al. Endothelial interactions of neutrophils under flow in chronic obstructive pulmonary disease. Eur Respir J 2005; 25: 612-617.

45 Sapey E, Ahmad A, Bayley D, et al. Imbalances between interleukin-1 and tumor necrosis factor agonists and antagonists in stable COPD. J Clin Immunol 2009; 29: 508-516.

46 Beeh KM, Beier J, Kornmann O, et al. Long term repeatability of induced sputum cells and inflammatory markers in stable, moderately severe COPD. Chest 2003; 123: 778-783.

47 Parmer JS, Mahadeva R, Reed BJ, et al. Polymers of $\alpha_{1}$-antitrypsin are chemotactic for human neutrophils: a new paradigm for the pathogenesis of emphysema. Am J Respir Cell Mol Biol 2002; 26: 723-730.

48 Dirksen A, Dijkman JH, Madsen F, et al. A randomised clinical trial of $\alpha_{1}$-antitrypsin augmentation therapy. Am J Resp Crit Care Med 1999; 160: 1468-1472.

49 Kueppers F. The role of augmentation therapy in alpha-1 antitrypsin deficiency. Curr Med Res Opin 2011; 27: 579-588.

50 Dirksen A, Dijkman JH, Madsen F, et al. A randomised clinical trial of $\alpha_{1}$-antitrypsin augmentation therapy. Am J Respir Crit Care Med 1999; 160: 1468-1472.

51 Vestbo J, Prescott E, Lange P. Association of chronic mucus hypersecretion with FEV1 decline and chronic obstructive pulmonary disease morbidity. Copenhagen City Heart Study Group. Am J Respir Crit Care Med 1996; 153: 1530-1535.

52 Prescott E, Lange P, Vestbo J. Chronic mucus hypersecretion in COPD and death from pulmonary infection. Eur Respir J 1995; 8: 1333-1338.

53 Effros RM, Peterson B, Casaburi R, et al. Epithelial lining fluid solute concentrations in chronic obstructive lung disease patients and normal subjects. J Appl Physiol 2005; 99: 1286-1292.

54 Pinto-Plata V, Toso J, Lee K, et al. Profliling serum biomarkers in patients with COPD. Associations with clinical parameters. Thorax 2006; 61: 23-28.

55 Franciosi LG, Page CP, Celli BR, et al. Markers of disease severity in chronic obstructive pulmonary disease. Pulm Pharmacol Ther 2006; 19: 189-199. 